\title{
Analysis of the Interaction of Vinyl and Carbonyl Silanes with Carbon Nanofiber
}

\section{Surfaces}

Andrés NISTAL*, Cristina PALENCIA, Mª Alejandra MAZO, Fausto RUBIO, Juan RUBIO, José Luis OTEO

Department of Chemistry Physics of Surfaces and Processes. Instituto de Cerámica y Vidrio (CSIC), Kelsen 5, 28049 Madrid, Spain.

\section{$\underline{\text { Abstract }}$}

Carbon Nanofibers (CNFs) have been treated with vinyltryethoxy silane (VTS) and 3metacryloxypropyltrimethoxy silane (MPS). CNF-silane interactions have been analyzed by means of TGA, FTIR-ATR, TEM, HRTEM, SEM and nitrogen adsorption. For similar silane concentration solutions TG analysis has shown that VTS and MPS form one and three silane monolayers, respectively. This has also been corroborated by the presence of an FTIR-ATR band at $1250 \mathrm{~cm}^{-1}$ assigned to $\mathrm{Si}-\mathrm{O}-\mathrm{Si}$ bonds of silica layers. For low silane concentrations, the vinyl group of VTS is bonded to the graphene CNF surface mainly through $\Pi-\Pi$ interactions. However, MPS interacts through the carbonyl group with hydroxyl groups of graphene defect sheets existing probably in micropores. Silanol-CNF hydroxyl interactions are also expected at these silane concentrations. For high silane concentration, when the silica layer is formed, both silanes present vinyl free and carbonyl free groups, as observed by the $1370 \mathrm{~cm}^{-1}$ and $1686 \mathrm{~cm}^{-1}$ FTIR-ATR bands, respectively. Nitrogen adsorption has shown that while VTS is adsorbed mainly on the defect free

\footnotetext{
* Corresponding author. Tel.: +34 917355840; Fax: +34 917355843. E-mail address: andresnistal@icv.csic.es
} 
graphene surface, MPS is adsorbed on the micropores and, therefore on the hydroxyl defect graphene sites. These results are finally correlated with the dispersion stability of both silanes on water and styrene solutions.

\section{Introduction}

Carbon nanotubes (CNTs) and related carbon nanostructures such as carbon nanofibers (CNFs) have attracted much attention since the landmark paper by Iijima in 1991 [1]. Derived from their $\mathrm{sp}^{2}$ carbon structure and nanometer size those materials exhibit interesting and unusual physicochemical properties [2, 3]. Among others, we can emphasize their electrical and thermal conductivity [4], their outstanding high mechanical strength, flexibility and high aspect ratio [5]. Due to these properties CNF/CNT are consider as promising fillers in composite materials science. Although CNF properties are not as good as $\mathrm{CNT}$ are, the highest production rate and the lowest price of CNF site them closer in time to realistic composite market scenarios. Unfortunately there are still some drawbacks to face. The chemical structure of as-prepared CNF/CNT entails a poor dispersion in different solvents as well as in matrix phases. On the other hand, the chemical inertness of those materials results in a poor interaction with the matrix and the expected mechanical properties decrease. Surface functionalization is an option to solve these problems, as surface bonded functional groups can enhance the dispersion and allows stronger $\mathrm{CNF} /$ matrix interactions. $\mathrm{CNF} / \mathrm{CNT}$ surface functionalization can be made through two different strategies $[6,7]$. One is the non-covalent wrapping of carbon nanostructures with different kind of molecules, such as surfactants [8] or polymers [9]. Other possibility is the covalent functionalization through different reactions [10]. Covalent functionalization can be carried out by reacting the required chemical structure with the $\mathrm{sp}^{2}$ surface carbon atoms or through functional groups at the CNF surface. Many authors have reported different 
methods to generate functional groups in CNF surface, for example as a consequence of the purification step by the oxidative reaction with inorganic acids [7], by reaction with ozone [11] or by fluorination reactions [12]. The most common strategy is to oxidize the carbonaceous surface by reaction with inorganic acids, leading to carboxylic acids formation. Once the acid is formed it can be derivatized to the acid derivate by reaction with thionyl chloride. Acid derivatives are proved to react in high yields with alcohols and amines, resulting in the ester or amide linkage respectively. The possibilities of such functionalization are wide, but in contrast many steps are involyed. Taken into account this result, one interesting alternative is $\mathrm{CNF}$ organophilization with silane coupling agents (SCA). Once the silane is hydrolyzed it may condensate with hydroxyl and carboxylic acid groups forming stable covalent bonds. The non-hydrolyzable substituent remains available for covalent reaction or physical interaction with matrix phases. The main advantages of this process are based on its simplicity and the enormous amount of different silanes that are available. Many works have been published using SCA on glass-fiber since last decades [13-17] and more recently on carbonaceous surfaces [18-23]. Velasco-Santos et al. [18] functionalized MWCNTs with 3-mercaptopropyltrimethoxy silane. They showed that the functionalization process did not affect the crystalline structure of the MWCNTs treated. Ma et al. [19] functionalized MWCNTs with 3-glycidoxypropyltrimethoxy silane. They obtained improved dispersion stability in ethanol. Bag et al. [20] functionalized MWCNTs with 3-methacryloxypropyltrimethoxy silane (MPS) and confirmed the result of the silanization process by means of FTIR, SEM, EDS and TEM analysis. Palencia et al. [23] functionalized $\mathrm{CNF}$ with 3-aminopropyltriethoxy silane, 3-aminopropyltrimetoxy silane, $\mathrm{N}$ (2-aminoethyl)-3-(aminopropyltrimethoxy silane) and 3-glycidoxypropyltrimethoxy silane. They evidenced the presence of carboxylic acid and hydroxyl groups on the CNF surface as 
impurities or defects and silanized the CNFs in only one single step. The silanization process was evidenced by means of FTIR-ATR, XPS, SEM and TEM analysis. The aim of the present work is to study the incorporation of two new silanes to be used for further polymerization with polyester resins. These silanes, MPS and vinyltriethoxy silane (VTS) present an $\alpha-\beta$ insaturated carbonyl group and a vinyl one, respectively. The silanization process was carried out in only one single step, as C. Palencia et al. [23] proved that is possible. The incorporation of the silanes was studied by means of TGA, FTIR-ATR, surface area measurements and SEM/TEM analysis. It has been also analysed the effect of the vinyl group present on both silanes, their interaction and orientation on the CNF surface, and the formation of a silica layer coating the $\mathrm{CNF}$.

\section{Experimental}

\subsection{Materials}

The CNFs used in this study were manufactured by Grupo Antolín Ingeniería (Burgos, Spain) in a floating catalyst reactor using natural gas as a carbon feedstock and $\mathrm{Ni}$ as catalyst at temperatures above $1100{ }^{\circ} \mathrm{C}$. This sample has been deeply characterized elsewhere [24]. The CNFs were used without any further purification. SCA used in this work were MPS and VTS and both were purchased from ABCR (both silanes at 98\% purity) and used as received without further purification.

\subsection{Methods}

Seven silane solutions were prepared for each silane, adding to $100 \mathrm{ml}$ of deionized destilled water with $0.01,0.03,0.1,0.5,1,2$, and $5 \mathrm{~g}$ of MPS or VTS respectively. Then, the mixture was stirred at $600 \mathrm{rpm}$ for 60 minutes at room temperature since it is known that it is an appropriate hydrolysis time [25]. Next, $5 \mathrm{~g}$ of CNFs were added, stirred for one minute 
under the same conditions and then filtered. Samples were dried in an oven at $110^{\circ} \mathrm{C}$ during $48 \mathrm{~h}$ and then kept in moisture free ambient for further characterization.

A $0.5 \%(\mathrm{w} / \mathrm{w})$ suspension of the pristine and silanized CNF was prepared in order to estimate the dispersion stability in water and styrene. The samples were sonicated 15 minutes before measurements.

\subsection{Characterization techniques}

TGA measurements were carried out using a Perkin Elmer Pyris 1 TGA analyzer at a heating rate of $10{ }^{\circ} \mathrm{C} / \mathrm{min}$ between 25 and $800{ }^{\circ} \mathrm{C}$ and a synthetic air flow of $20 \mathrm{ml} / \mathrm{min}$.

Isotherms of adsorption-desorption of $\mathrm{N}_{2}$ at $77 \mathrm{~K}$ were measured using a Micromeritics TriStar 3000 model. The BET areas $\left(S_{\mathrm{BET}}\right)$ were determined using the Brunauer, Emmett and Teller equation [26]. Mesopore size distributions (PSD), i.e. pores between 2-100 nm, were obtained with the method of Barret, Joyner and Halenda (BJH) [26]. Mesopore surface areas $\left(\mathrm{MS}_{\mathrm{BHJ}}\right)$ and average pore diameters $\left(\mathrm{d}_{\mathrm{BJH}}\right)$ were also calculated assuming cylindrical pores.

FTIR-ATR spectra were carried out in a Perkin Elmer FTIR spectrometer using the MIRacle $^{\mathrm{TM}}$ attenuated total reflectance device. Ten scans were used to obtain each spectrum and background was subtracted from all spectra. The resolution was $4 \mathrm{~cm}^{-1}$ in the spectral range $4000-600 \mathrm{~cm}^{-1}$. In order to analyze in more detail the IR bands of any silane adsorbed on the CNFs, FTIR-ATR difference spectra were used. These difference spectra were obtained by subtracting the corresponding spectra of any treated sample with the one of pristine CNFs. It is well-known that the use of difference spectra is a very powerful technique for amplifying the effect of any chemical treatments on a sample. This procedure is especially useful in the case of surface studies where low concentration of functional groups is involved. Thus, although original spectra do not clearly indicate the changes 
arising after silane treatment, the FTIR-ATR difference spectra between the silane treated CNFs and untreated ones make possible to unambiguously assign bands [27]. This procedure was firstly used by Ishida with silane coated glass fibers [13-16] and it has also been used for CNFs coated with amine and epoxy silanes [23].

Field emission scanning electron microscopy (FE-SEM) was carried out using a field emission scanning microscope (FE-SEM Hitachi 4700) operating at $20 \mathrm{keV}$. Conventional Transmission Electron Microscopy (TEM) was carried out in a Hitachi H-120 transmission electron microscope, operating at $125 \mathrm{kV}$, while High Resolution Transmission Electron Microscopy (HRTEM) was performed with a JEOL JEM-2010 model operating at $200 \mathrm{kV}$.

Sonication was carried out with a Branson 5200 water bath working at $47 \mathrm{KHz} \pm 6 \%$. Dispersion measurements were estimated by means of the change in the absorbance with time at $667 \mathrm{~nm}$ in a Perkin Elmer Lambda $25 \mathrm{UV} / \mathrm{Vis}$ spectrometer. One single point was measured every minute for $25 \mathrm{~h}$.

\section{Results and discussion}

\subsection{TG analysis}

From the TG results it is possible to obtain the amount of SCA incorporated on the $\mathrm{CNF}$, due to the fact that the organic part burns or decompose at lower temperature than the graphitic CNF [28]. Figure 1 shows the TG plots of CNF coated with MPS and VTS silanes. Here it can be observed that the TG of pristine CNF only presents a main weight loss starting close to $450{ }^{\circ} \mathrm{C}$ that ends at about $680^{\circ} \mathrm{C}$. However, for silane coated CNF the TG plots present two weight losses not present in pristine CNF TG plot. Weight losses below $450{ }^{\circ} \mathrm{C}$ are associated with the silane decomposition and the main one, above this temperature, is due to the CNF degradation, as it has been mentioned before. As it can be seen in Figure 1, the more MPS added, the more incorporated. In the case of VTS the trend 
is similar to that of MPS, but only a small amount of silane is incorporated. In Figure 1 it is also observed that weight losses due to silane decomposition appear at different temperatures depending on the type of silane and its concentration on the CNF. These decomposition temperatures have been calculated by using the first derivative of TG curves.
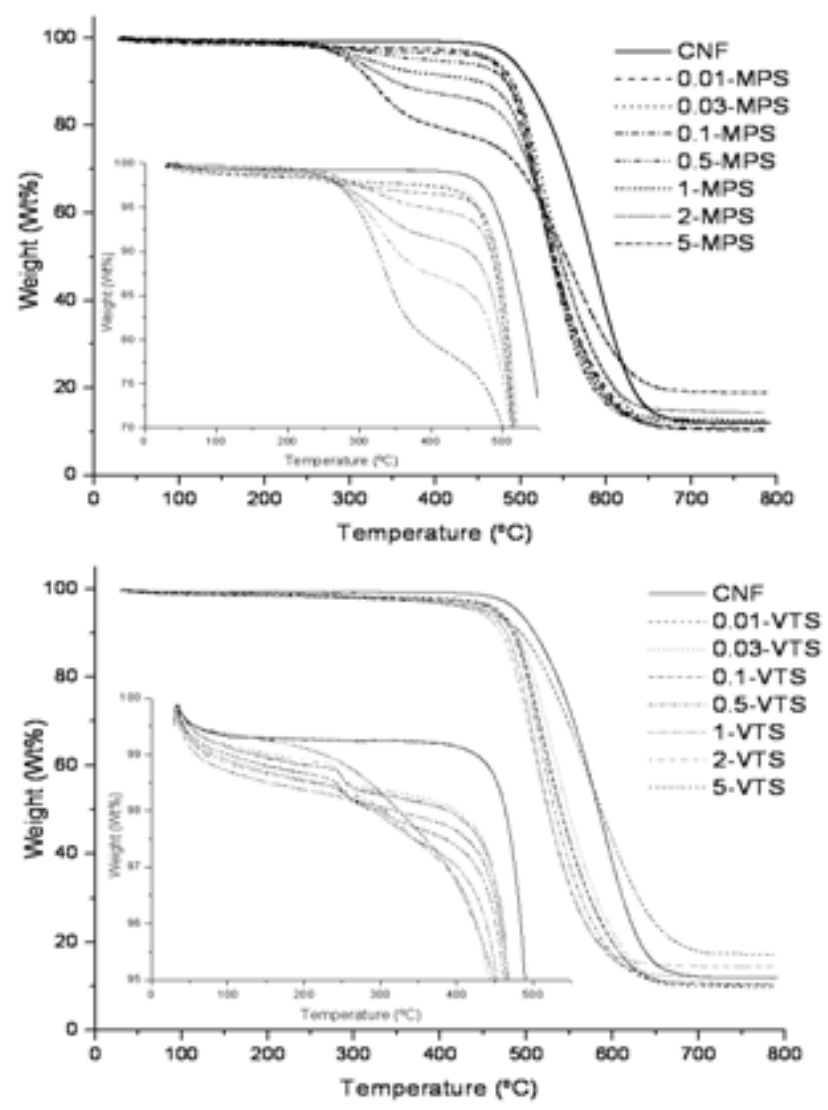

Figure 1. TGA of CNF coated with MPS and VTS.

In Figure 2 the first derivative TG plots of MPS and VTS coated CNF are shown for the temperature range where both silanes decompose. In both cases there are two weight losses besides the one associated to the CNF degradation, that is not shown due to the plotted temperature range. The first weight loss is located between 250 and $280{ }^{\circ} \mathrm{C}$, and the second one at around 310 and $330{ }^{\circ} \mathrm{C}$ for MPS and VTS silanes. The first weight loss seems 
to be present for every silane coated CNF, while the second one appears when CNFs are treated with at least $0.5 \%$ silane $(\mathrm{w} / \mathrm{w})$ solution. Therefore, the decomposition temperature range chosen to calculate the amount of silane incorporated depends on the silane type and concentration. Table 1 gives the amount of silane incorporated onto the CNF surface as well as the equivalent layers of silane (ELS). According to Naviroj et al. [29] ELS can be calculated knowing the BET area of CNFs $\left(169.5 \mathrm{~m}^{2} / \mathrm{g}\right)$, the number of molecules on the surface and an approximate molecular size. The estimated areas occupied by a VTS or a MPS molecule are $0.4 \mathrm{~nm}^{2} /$ molecule and $0.5 \mathrm{~nm}^{2} /$ molecule, respectively [29]. These areas were estimated by Miller and Ishida [30] using the molecular-mechanics software system CHEMLAB, and in this work we have now used a new software system (CHEMDRAW) obtaining similar results. In both software systems the micromechanics model assumes that silane molecules may be projected with normal or parallel orientations to the plane of the substrate surface. However, as it will be discussed below the main orientation is the parallel one for both MPS and VTS silanes on the studied CNFs and then, this orientation has been used to calculate the ELS in this work. Therefore, assuming that this micromechanics model can be used with a nanoscale substrate, the ELS have been calculated in such way. 

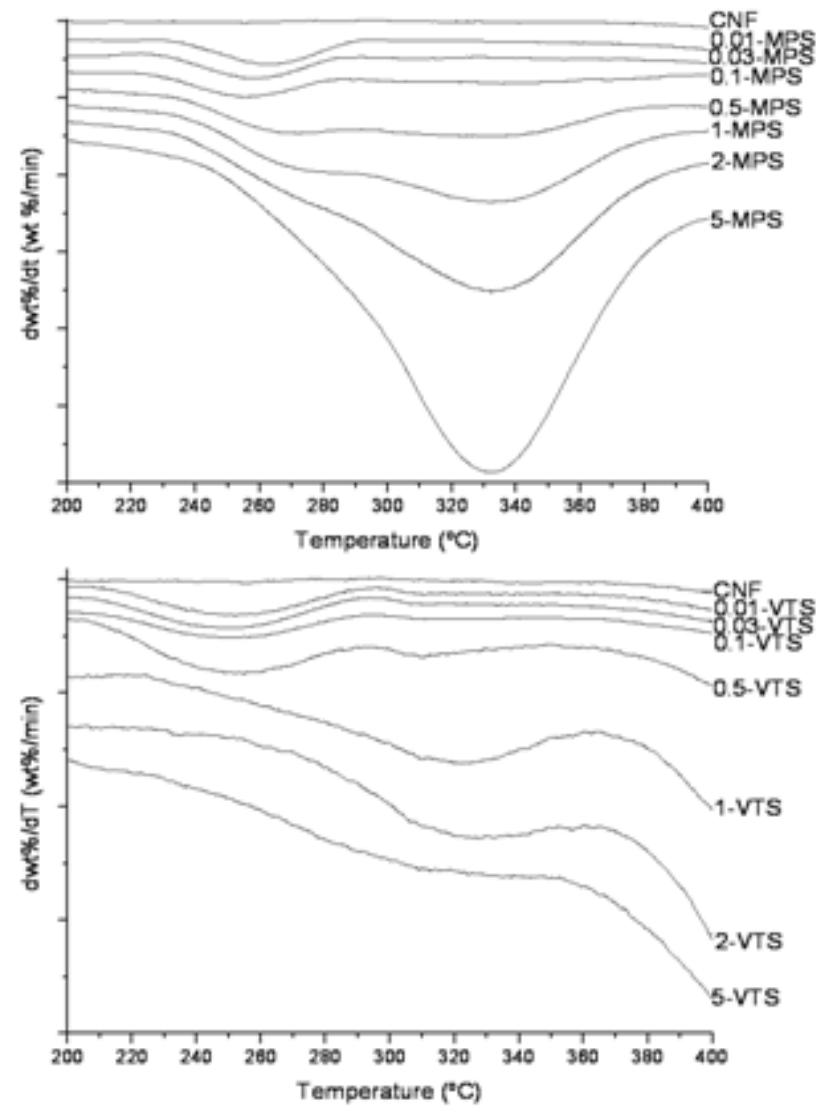

Figure 2. First derivative plots of TGA of CNF coated with MPS and VTS.

The above mentioned two weight losses in the first derivative of TG curves suggest that as the amount of silane incorporated increases, a silica layer can be formed on the CNF surface. If low silane concentration is coating the CNF surface, the silane organic chain decomposes at a temperature around $250-280{ }^{\circ} \mathrm{C}$ when heating open to air. Nevertheless, if a higher amount of silane is incorporated, a silica multilayer can be formed on the CNF surface. Thus, when a silane multilayer is formed, the outer silane molecules give the first peak appearing at $250-280^{\circ} \mathrm{C}$, and the inner silane layers give the second peak, appearing at $310-330^{\circ} \mathrm{C}$. Therefore, the first weight loss is always present in all silane coated CNF, while the second one is only present when a silane multilayer is formed on the CNF surface. This conclusion will be corroborated by FTIR-ATR results discussed below. Temperature 
ranges used to calculate the amount of incorporated silane, first derivative TG peaks, and ELS results are given on Table 1.

Table 1. TG results for the incorporation of SCA on CNF. (IDT: Initial decomposition temperature. EDT: Ending decomposition temperature).

\begin{tabular}{|c|c|c|c|c|c|c|c|}
\hline \multirow{2}{*}{ Silane } & \multirow{2}{*}{ Sample } & \multicolumn{2}{|c|}{ T range $^{\mathrm{a}}$} & \multicolumn{2}{|c|}{$\mathrm{T}$ of maximum } & \multirow{2}{*}{$\begin{array}{l}\% \text { Silane } \\
\text { Incorporated }^{b}\end{array}$} & \multirow{2}{*}{ ELS $^{c}$} \\
\hline & & $\begin{array}{l}\text { IDT } \\
\left({ }^{\circ} \mathrm{C}\right)\end{array}$ & $\begin{array}{l}\text { EDT } \\
\left({ }^{\circ} \mathrm{C}\right)\end{array}$ & $\begin{array}{l}1^{\text {st }} \text { weight } \\
\text { loss }\left({ }^{\circ} \mathrm{C}\right)\end{array}$ & $\begin{array}{c}2^{\text {nd }} \text { weight } \\
\text { loss }\left({ }^{\circ} \mathrm{C}\right)\end{array}$ & & \\
\hline- & $\mathrm{CNF}$ & 450 & 682 & 588 & - & - & - \\
\hline \multirow{7}{*}{ MPS } & 0.01-MPS & 230 & 295 & 260 & - & 0.66 & 0.09 \\
\hline & 0.03-MPS & 227 & 290 & 257 & - & 0.61 & 0.09 \\
\hline & 0.1-MPS & 225 & 285 & 254 & - & 0.78 & 0.11 \\
\hline & 0.5-MPS & 230 & 385 & 270 & 330 & 4.16 & 0.58 \\
\hline & 1-MPS & 230 & 400 & 277 & 330 & 7.23 & 1.01 \\
\hline & 2-MPS & 227 & 413 & 273 & 330 & 11.73 & 1.64 \\
\hline & 5-MPS & 220 & 420 & 275 & 331 & 20.48 & 2.87 \\
\hline \multirow{6}{*}{ VTS } & 0.01-VTS & 204 & 297 & 250 & - & 0.52 & 0.27 \\
\hline & 0.03-VTS & 201 & 296 & 249 & - & 0.53 & 0.28 \\
\hline & $0.1-\mathrm{VTS}$ & 201 & 296 & 249 & - & 0.58 & 0.31 \\
\hline & 0.5-VTS & 200 & 350 & 256 & 310 & 0.86 & 0.45 \\
\hline & 1-VTS & 219 & 366 & 273 & 322 & 0.99 & 0.52 \\
\hline & 2-VTS & 227 & 367 & 280 & 330 & 1.18 & 0.62 \\
\hline
\end{tabular}




\begin{tabular}{|l|c|c|c|c|c|c|c||}
\cline { 2 - 7 } & 5 -VTS & 195 & 354 & 273 & 328 & 1.88 & 0.99 \\
\hline
\end{tabular}

${ }^{\mathrm{a}}$ Calculated from the first derivative plot of TGA.

${ }^{\mathrm{b}}$ Calculated from TGA.

${ }^{\mathrm{c}}$ Calculated according to Naviroj et al. [29].

\subsection{FTIR-ATR analysis}

Figure 3 show the FTIR-ATR spectrum of pristine CNFs and the corresponding difference spectra of MPS silanized CNFs. In the pristine CNF spectrum some absorption bands indicate the presence of oxygenated functional groups on the CNF surface. There is an absorption band at $1074 \mathrm{~cm}^{-1}$ associated to the presence of $\mathrm{C}-\mathrm{O}$ bonds in alcoholic groups. Close to $1180 \mathrm{~cm}^{-1}$ there is a band assigned to the $\mathrm{C}-\mathrm{O}$ bond in phenol groups. Between 1400 and $1495 \mathrm{~cm}^{-1}$ there is a broad band that is due to the presence of the $\mathrm{C}=\mathrm{C}$ bonds on the CNF structure. Finally, between 1595 and $1800 \mathrm{~cm}^{-1}$ there is a broad band that is assigned to the $\mathrm{C}=\mathrm{O}$ bonds present in carboxyl, lactone or conjugated ketone groups [31]. The presence of such groups must be taken into account since they can condensate with Si$\mathrm{OH}$ groups of the hydrolyzed SCA molecules and therefore remain covalently bonded to the CNF surface. This condensation reaction has already been demonstrated by means of XPS measurements [23].

FTIR-ATR difference spectra MPS silanized CNF are also shown in Figure 3. It is clear that MPS is present on the surface on the CNF due to the presence of the absorption bands located at $1665 \mathrm{~cm}^{-1}$ and $1620 \mathrm{~cm}^{-1}$ assigned to the stretching vibrations of $\mathrm{C}=\mathrm{O}$ and $\mathrm{C}=\mathrm{C}$ bonds, respectively. Bands attributed to stretching of Si-O-Si bonds (at 1080 and 1180 $\left.\mathrm{cm}^{-1}\right)$ are also observed $[15,22,32-36]$. For the 0.01-MPS, 0.03-MPS and 0.1-MPS samples, the difference spectra are very similar due to the small amount of MPS 
incorporated on the CNF surface. It is possible to distinguish the $\mathrm{Si}-\mathrm{O}-\mathrm{Si}$ bands but those associated to the $\mathrm{C}=\mathrm{O}$ and $\mathrm{C}=\mathrm{C}$ bonds are overlapped. A deconvolution procedure was carried out to analyse both bands, and it will be discussed later.

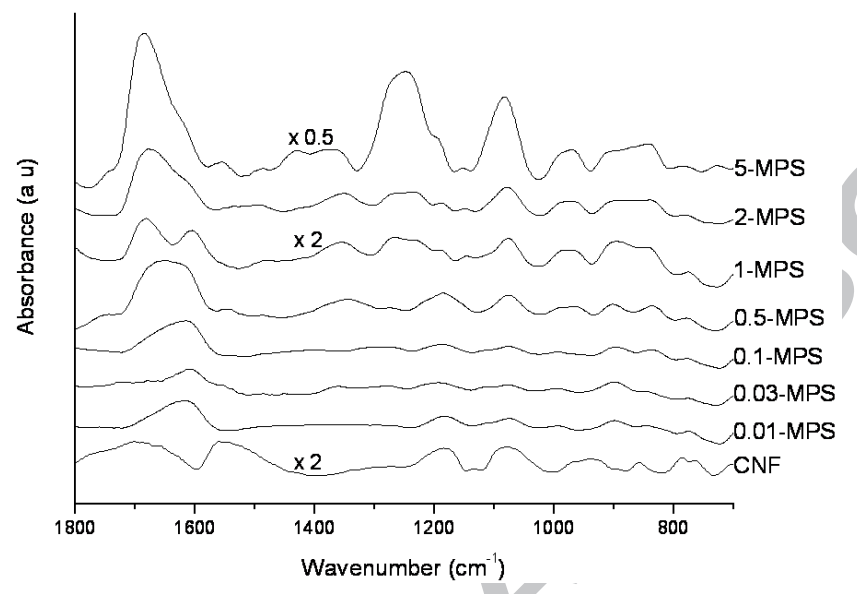

Figure 3. FTIR-ATR spectrum of pristine CNFs and difference spectra of MPS coated CNFs.

The 0.5-MPS difference spectrum shows intense bands, due to the higher amount of MPS incorporated. In this case overlapping of $\mathrm{C}=\mathrm{O}$ and $\mathrm{C}=\mathrm{C}$ bands still occurs, but is noticeable the higher contribution of the $\mathrm{C}=\mathrm{O}$ band that blue-shifts respect to the above mentioned samples. Finally, the 1-MPS, 2-MPS and 5-MPS difference spectra show high intensities for the all above mentioned bands, and a new band located close to $1250 \mathrm{~cm}^{-1}$ appears with a high intensity too. The assignation of this new band has been carried out in accordance with Tian et al. [37]. They showed that the Si-O bonds from silica, silane/silica interface and silane-silane polymer overlap in the $1000-1260 \mathrm{~cm}^{-1}$ spectral region. However, if an oblique incidence at the Brewster angle is used and then p-polarized radiation is preferentially transmitted, the longitudinal optical (LO) and transverse optical (TO) phonon modes are well separated and the LO mode makes possible to characterize the newly 
formed $\mathrm{Si}-\mathrm{O}$ bonds at the silane-substrate interface [38-40]. Tian et al., showed that in differential FTIR-ATR spectra the TO phonon mode is a highly variable band appearing at $1000-1150 \mathrm{~cm}^{-1}$, however the LO phonon mode is a sharper feature appearing at $1200-1260$ $\mathrm{cm}^{-1}$. The peak assignment in the TO band is difficult because of contributions from several species, including $\mathrm{Si}-\mathrm{O}-\mathrm{Si}$ and $\mathrm{Si}-\mathrm{O}-\mathrm{C}$ vibrations [41-44]. In contrast, the sharp LO band appears consistently in the differential spectra as new Si-O bonds are formed at the silane/substrate interface. After silane adsorption on a substrate, only direct bonding of the silane molecules to the substrate can add intensity to the LO band, and polycondensed silanes do not contribute any additional features in the region of the $\mathrm{Si}-\mathrm{O}-\mathrm{Si} \mathrm{LO}$ mode. However, simple polycondensation of silane films do not show any change in the LO region despite considerable increase in the TO band. Besides, direct bonding of silane molecules to the substrate give an important blue-shift of the LO mode but the TO one does not change. Therefore, when LO modes intensify and blue-shift after silane adsorption the oxide thickness is increased.

In accordance with Tian et al., the $1180 \mathrm{~cm}^{-1}$ band corresponds to clusters of MPS molecules polycondensed on the CNF surface, and the $1250 \mathrm{~cm}^{-1}$ band corresponds to the formation of a Si-O-Si layer covering the CNF surface. The observation of the $1250 \mathrm{~cm}^{-1}$ band for the 1-MPS sample indicates that a silica coating is formed when the concentration of MPS is between 0.5 and $1 \%$. For concentrations higher than $1 \%$, i. e. for $2-$ MPS and 5MPS samples, the frequency of the LO peak is similar but its intensity increases, showing that all new adsorbed MPS molecules do not contribute to increase the silica coating thickness, and they are only polycondensed over the first coating Error! Bookmark not defined. [38]. These results corroborate the above discussed TG ones, where it was concluded that a silica layer can be formed when the CNFs were coated with 0.5 to $1 \%(\mathrm{w} / \mathrm{w})$ of MPS (Table 1$)$. 
A similar blue-shift occurs with the $1665 \mathrm{~cm}^{-1}$ band assigned to $\mathrm{C}=\mathrm{O}$ bonds. This band blue-shifts from 1665 to $1686 \mathrm{~cm}^{-1}$ when the MPS concentration increases on the CNF surface. However, in this case such blue-shift is associated to the interaction of the $C=O$ bond on the CNF surface. Several authors have shown that when the $\mathrm{C}=\mathrm{O}$ bond is physically adsorbed or hydrogen bonded on a solid surface it appears at a lower frequency that when it is as $\mathrm{C}=\mathrm{O}$ free or non-hydrogen bonded $[17,32,45]$, and therefore the blueshift observed in Figure 3 is due to the orientation of the MPS molecules on the CNF surface. Then, for low MPS adsorbed concentrations most part of the MPS molecules are hydrogen bonded to the CNF surface and probably on the acid surface sites existing on it, since their presence has been demonstrated by ATR-FTIR spectra shown in Figure 3. However, as more MPS molecules are adsorbed on the CNF surface, more free carbonyl groups are present. This conclusion is supported by the intensity ratio between the bands assigned to $\mathrm{C}=\mathrm{O}$ and $\mathrm{C}=\mathrm{C}$ groups, plotted against ELS results in Figure 4. As it can be seen, the relative intensity of the $\mathrm{C}=\mathrm{O}$ band increases with the amount of MPS incorporated. This is due to the fact that the carbonyl band is much more intense than the vinyl one. As the amount of MPS increases the overlapping between those bands decreases, a result that is due to the blue-shift observed in the $\mathrm{C}=\mathrm{O}$ band when is not hydrogen bonded (see Figure 3 ).

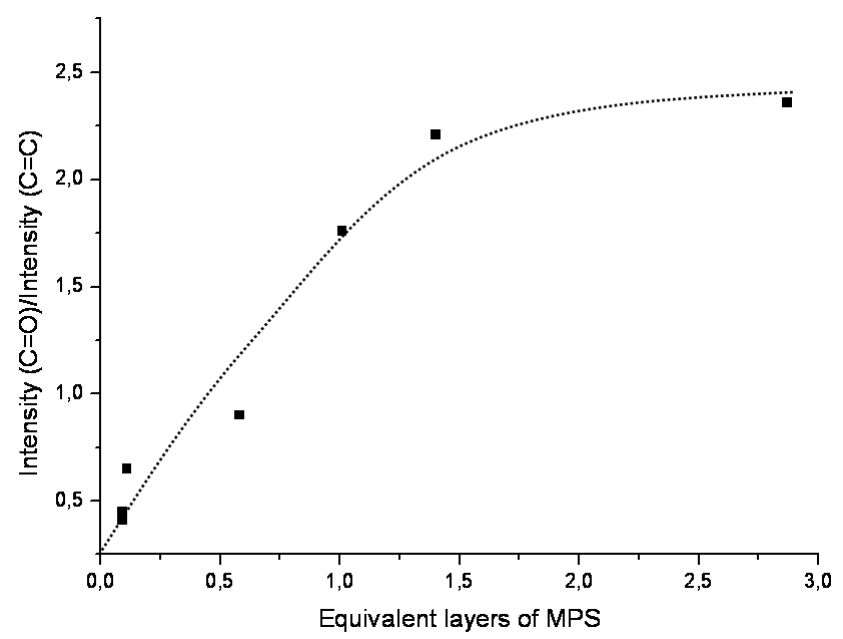


Figure 4. Relation in intensity of the bands associated to $\mathrm{C}=\mathrm{C}$ and $\mathrm{C}=\mathrm{O}$ groups is plotted against the equivalent layers of MPS on the silanized CNF (line is only for guiding the eye).

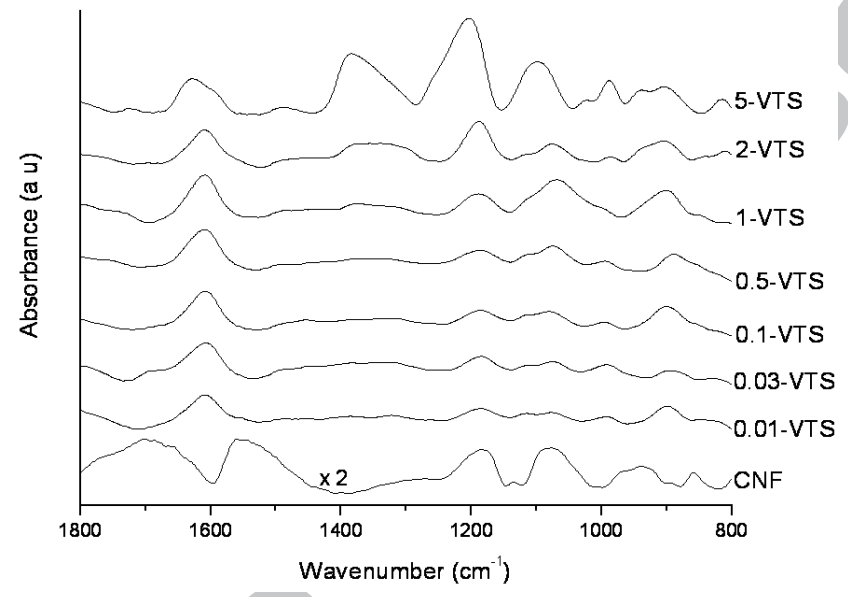

Figure 5. FTIR-ATR spectrum of pristine CNFs and difference spectra of VTS coated CNFs.

FTIR-ATR difference spectra of VTS silanized CNF are shown in Figure 5. The FTIR-ATR spectrum of the pristine CNFs is also included in this Figure. The band at 1620 $\mathrm{cm}^{-1}$, assigned to the $\mathrm{C}=\mathrm{C}$ stretching mode is present in every difference spectra. Close to $1370 \mathrm{~cm}^{-1}$ is located the absorption band assigned to the deformation of the $\mathrm{C}=\mathrm{CH}_{2}$ group, and it is only observed for the higher VTS coated CNF. Also the bands assigned to Si-O bonds are present at 1080 and $1190 \mathrm{~cm}^{-1}$, which are due to the TO and LO optical phonon modes of the Si-O-Si bonds, respectively. Both bands show a blue-shift close to $20 \mathrm{~cm}^{-1}$ for the highest VTS adsorbed concentration. Taken into consideration the above mentioned results for MPS and the blue-shift of the Si-O-Si LO band, it must be concluded that only 
for the 5-VTS sample the silica coating is thick enough to complete a silica layer, a result that corroborates the theoretical ELS results of Table 1. At the same time, the second decomposition temperature peak found in the derivative TG analysis for the 1-VTS and 2VTS samples must be assigned to polycondensed VTS molecules but not forming a silica layer. Thus, blue-shifts for MPS and VTS are of 60 and $20 \mathrm{~cm}^{-1}$, respectively, showing that the MPS forms a thicker silica coating on the CNF surface than VTS does.

An interesting feature observed in the FTIR-ATR spectra of MPS and VTS adsorbed silanes is that the $\mathrm{C}=\mathrm{CH}_{2}$ stretching mode appears close to $1620 \mathrm{~cm}^{-1}$ for both silanes, but the $\mathrm{C}=\mathrm{CH}_{2}$ in-plane deformation is only observed for high adsorbed silane concentrations. In the case of the VTS silane, the $\mathrm{C}=\mathrm{CH}_{2}$ in-plane deformation band reaches higher intensity than the $\mathrm{C}=\mathrm{CH}_{2}$ stretching band. These results can also be described as those given for the $\mathrm{C}=\mathrm{O}$ bonds. The interaction of both silanes on the $\mathrm{CNF}$ surface can take place through $\mathrm{Si}-\mathrm{OH}$ groups of hydrolyzed silane and $\mathrm{OH}$ groups such as $\mathrm{COOH}, \mathrm{C}-\mathrm{OH}$, etc., existing as active sites on the pristine CNF surface, as it has been discussed previously from the FTIR-ATR spectrum (Figure 3). However, both silanes can also be adsorbed by the $\mathrm{C}=\mathrm{CH}_{2}$ group, and the MPS also by the $\mathrm{C}=\mathrm{O}$ group, as it has been described before. Such molecular configurations are showed in Figure 6. The interaction of the $\mathrm{C}=\mathrm{CH}_{2}$ group on the CNF surface could be on the graphene layer or between the $0.34 \mathrm{~nm}$ graphene interlayer separations [46] through stacking П-П interactions. Papirer et al. [47] have shown the higher interaction of unsaturated $\mathrm{C}=\mathrm{C}$ bonds on the surface of different types of carbons. This interaction can modify the in-plane deformation vibration of the $\mathrm{C}=\mathrm{CH}_{2}$ bonds but not the stronger intensity band of the $\mathrm{C}=\mathrm{CH}_{2}$ stretching of FTIR-ATR spectra. When the silane concentration existing on the CNF surface is higher than a monolayer or when several silane molecules are polycondensed over other ones directly adsorbed on the CNF surface, then 
the $\mathrm{C}=\mathrm{CH}_{2}$ in-plane deformation is free to vibrate and give its characteristic band close to $1370 \mathrm{~cm}^{-1}$. It is also observed a blue-shift of the in-plane $\mathrm{C}=\mathrm{CH}_{2}$ deformation from 1340 $\mathrm{cm}^{-1}$ to $1370 \mathrm{~cm}^{-1}$.

Finally, the bands associated to the stretching mode of the Si-OH group are present in every difference spectra at the $930-980 \mathrm{~cm}^{-1}$ frequency range for both silanes, indicating that the hydrolysis reaction has occurred and that not all Si-OH groups of such silanes have condensed forming Si-O-Si bonds. As the silane concentration increases, the Si-OH bands also do, as it is observed in Figures 3 and 5. 
a)

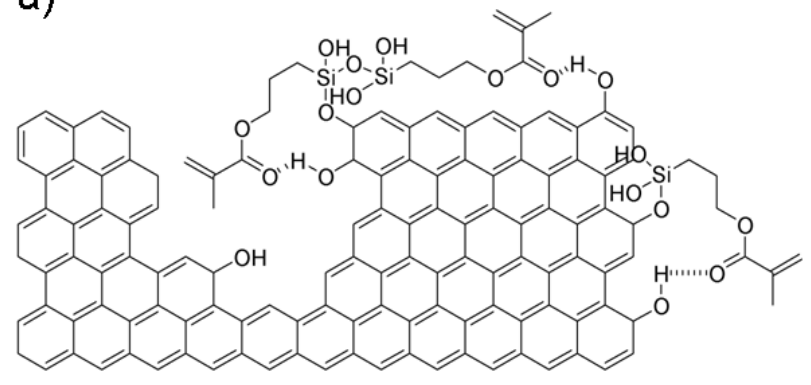

b)

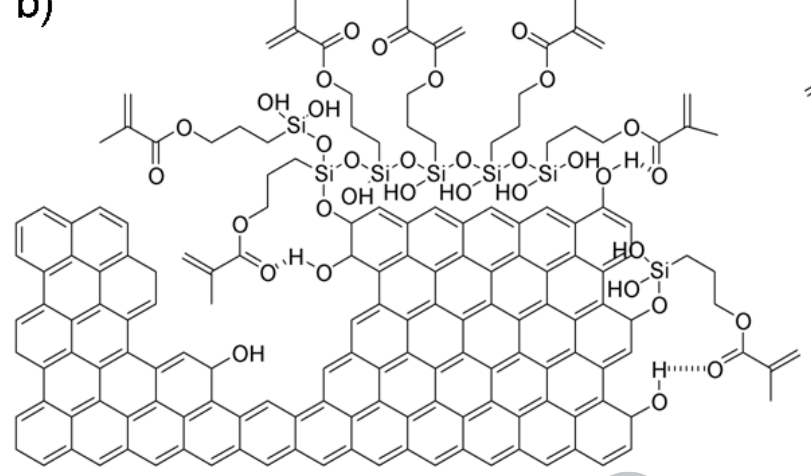

c)

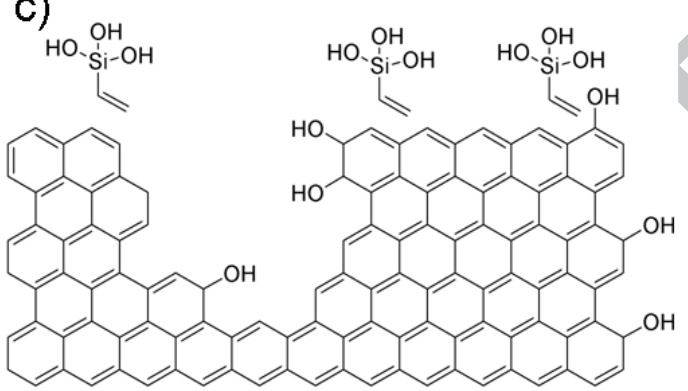

d)

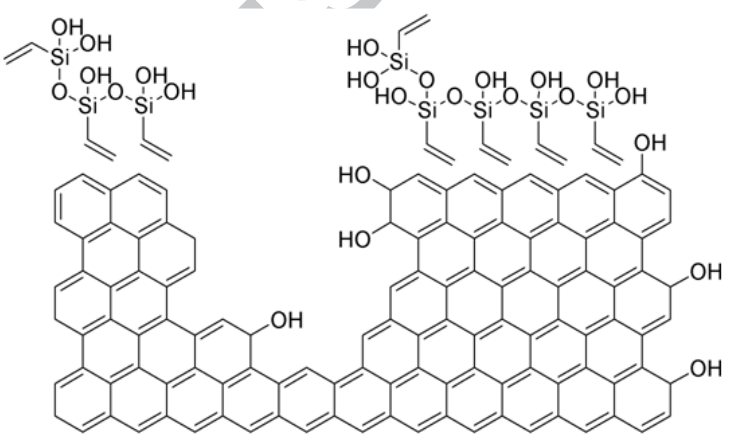

Figure 6. Schematic approach to the orientation of the silanes on the CNF surface, for low concentration of MPS (a), high concentration of MPS (b), low concentration of VTS (c) and high concentration of VTS (d).

In Figure 6 there are schematically shown the orientations of the MPS and VTS silanes adsorbed on the CNF surface. For low concentrations of silane, both silanes are preferentially oriented parallel relative to the CNF surface. This is due to the $\Pi-\Pi$ interaction between the $\Pi$ electron rich $\mathrm{CNF}$ surface and the vinyl group present in both silanes. In the case of the MPS coated CNF, this orientation is corroborated by the presence of the $1665 \mathrm{~cm}^{-1}$ band that corresponds to the hydrogen bonded $\mathrm{C}=\mathrm{O}$ adsorbed on the $\mathrm{CNF}$ surface. For high MPS or VTS concentrations polycondensation occurs and, due to the higher amount of silane incorporated there are some vinyl groups that do no give П-П interaction on the CNF surface. Therefore, when high amount of MPS or VTS is 
incorporated on the CNF surface, both silanes are preferentially oriented perpendicular relative to the CNF surface. Palencia et al. [23] concluded that pristine CNF have surface functional groups suitable to react with silanol groups, such as those detected by ATR-FTIR (see Figure 3). Moreover, they demonstrated that silanes were chemisorbed on CNF surface. Thus, C-O-Si groups are also present, as a result of the condensation between the silanol groups of the hydrolyzed silane and CNF surface hydroxyl groups. Also the hydrogen bonds between these CNF surface hydroxyl groups and the carbonyl group of the MPS are present because the $1660 \mathrm{~cm}^{-1}$ band remains.

\subsection{Surface area measurements}

The nitrogen adsorption-desorption isotherms on pristine CNF and SCA coated CNF are shown on Figure 7. These isotherms are Type IV characteristic, according to the IUPAC classification, with hysteresis loops initiating from the medium relative pressures $\left(\mathrm{P} / \mathrm{P}_{0} \approx\right.$ 0.45), and closing near $\mathrm{P} / \mathrm{P}_{0} \approx 1$. Patterns of the hysteresis loops seem to be of Type $\mathrm{H} 3$, which is often associated with capillary condensation in slit-shape mesopores [26]. 

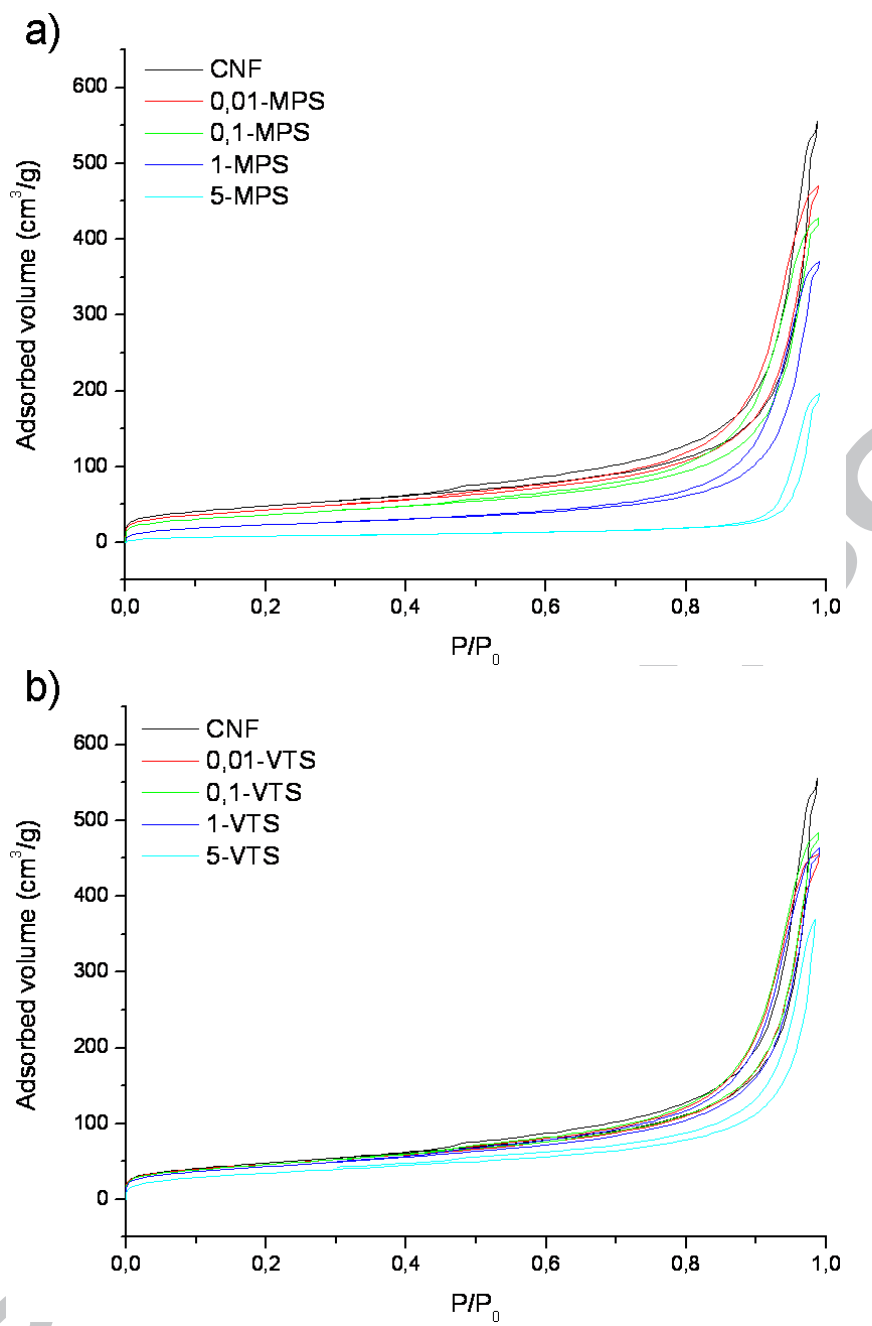

Figure 7. $\mathrm{N}_{2}$ adsorption-desorption isotherms of CNF coated with MPS (a) and VTS (b) coupling agents.

As it can be observed in Figure 7-a, the nitrogen adsorbed volume of the MPS coated CNF gradually decreases with the amount of MPS, showing that the MPS silane coats the pores of the CNF. On the other hand, the VTS coated CNF does not show such gradually decrease (Figure 7-b) except for that sample coated with the higher concentration of VTS. These results corroborate those found by TGA and FTIR-ATR analysis. 
From the nitrogen adsorption-desorption isotherms $\mathrm{S}_{\mathrm{BET}}, \mathrm{MS}_{\mathrm{BJH}}$ and $\mathrm{d}_{\mathrm{BJH}}$ values have been calculated. The $\mathrm{S}_{\mathrm{BET}}$ results are in line with the amount of silane incorporated or adsorbed on the CNF surface. As it was mentioned for Table 1, the amount of silane incorporated increases with the initial solution silane content and, from Table 2 it is observed that the $\mathrm{S}_{\mathrm{BET}}$ area decreases. This result indicates that the silane coating has been effective.

Table 2. $\mathrm{S}_{\mathrm{BET}}$ area, mesopore surface area $\left(\mathrm{MS}_{\mathrm{BJH}}\right)$ and average pore diameter $\left(\mathrm{d}_{\mathrm{BJH}}\right)$ for the pristine and silane coated $\mathrm{CNF}$.

\begin{tabular}{|c|c|c|c|c|}
\hline \multirow[b]{2}{*}{ Sample } & \multirow[b]{2}{*}{$\mathrm{S}_{\mathrm{BET}}\left(\mathrm{m}^{2} / \mathrm{g}\right)$} & \multicolumn{3}{|c|}{ Adsorption branch } \\
\hline & & $\begin{array}{l}\mathrm{MS}_{\mathrm{BJH}} \\
\left(\mathrm{m}^{2} / \mathrm{g}\right)\end{array}$ & $\begin{array}{c}\mathrm{S}_{\mathrm{BET}}-\mathrm{MS}_{\mathrm{BJH}} \\
\left(\mathrm{m}^{2} / \mathrm{g}\right)\end{array}$ & $\begin{array}{l}\mathrm{d}_{\mathrm{BJH}} \\
(\mathrm{nm})\end{array}$ \\
\hline$\overline{\mathrm{CNF}}$ & 169.5 & 1477.9 & 21.6 & 22.1 \\
\hline 0.01-MPS & 154.1 & 147.9 & 6.2 & 18.8 \\
\hline 0.03-MPS & 154.3 & 144.4 & 9.9 & 17.5 \\
\hline $0.1-\mathrm{MPS}$ & 131.4 & 130.8 & 0.6 & 19.4 \\
\hline $0.5-\mathrm{MPS}$ & 107.7 & 102.7 & 5.0 & 21.9 \\
\hline 1-MPS & 89.8 & 85.2 & 4.6 & 24.7 \\
\hline 2-MPS & 67.6 & 64.8 & 2.8 & 30.0 \\
\hline 5-MPS & 29.9 & 29.6 & 0.3 & 40.3 \\
\hline 0.01-VTS & 162.7 & 145.3 & 17.4 & 18.3 \\
\hline $0.03-$ VTS & 158.8 & 143.9 & 14.9 & 19.2 \\
\hline $0.1-\mathrm{VTS}$ & 163.4 & 151.9 & 11.5 & 18.8 \\
\hline
\end{tabular}




\begin{tabular}{|c|c|c|c|c|}
\hline $0.5-$ VTS & 156.6 & 145.3 & 11.3 & 18.9 \\
\hline $1-V T S$ & 153.7 & 140.5 & 13.2 & 19.4 \\
\hline 2 -VTS & 143.5 & 134.6 & 8.9 & 20.0 \\
\hline $5-V T S$ & 124.8 & 113.5 & 11.3 & 21.2 \\
\hline \hline
\end{tabular}

The hysteresis loops appeared in the nitrogen adsorption-desorption isotherms indicate the presence of mesopores in the CNF. $\mathrm{MS}_{\mathrm{BJH}}$ and $\mathrm{d}_{\mathrm{BJH}}$ values have been obtained from the adsorption branch of the corresponding nitrogen isotherms and they are given in Table 2. Here it is observed that $\mathrm{MS}_{\mathrm{BJH}}$ values are very close to $\mathrm{S}_{\mathrm{BET}}$ ones, showing that most part of the CNF surface area are due to mesopores. Differences between $\mathrm{S}_{\mathrm{BET}}$ and $\mathrm{MS}_{\mathrm{BJH}}$ values, given in Table 2, can be associated to the presence of micropores on the CNF. When CNF is coated with MPS silane most part of the micropores seems to be covered, but when it is VTS coated there is a given concentration that remains uncovered, independently of the amount of VTS incorporated. This result indicates not only a different interaction between MPS or VTS on the CNF surface, but also different locations to be adsorbed. This conclusion is now discussed in accordance to ATR-FTIR results.

CNFs are conformed mainly by defect free graphene sheets containing $\mathrm{sp}^{2}$ carbon atoms and as known, defects are related with $\mathrm{sp}^{3}$ carbon atoms in oxygenated groups. Taking that into account it is reasonable to assume that micropores formed by the conjunction of that graphene sheets may be locations of high degree of defects, generally oxygen functional groups containing $\mathrm{sp}^{3}$ carbon atoms. These groups are mainly hydroxyl such as phenol, carboxyl, etc., as detected by means of ATR-FTIR (see Figure 3). As it was commented from FTIR-ATR results, the interaction of MPS has occurred through its silanol groups as well as $\mathrm{C}=\mathrm{O}$ and $\mathrm{C}=\mathrm{C}$ bonds. On the other hand, VTS interacts with the $\mathrm{CNF}$ 
surface mainly by its $\mathrm{C}=\mathrm{C}$ vinyl group. Therefore, most of the VTS-CNF adhesion is due to $\Pi-\Pi$ interactions and some part are due to silanol-hydroxyl ones. Consequently, for low silane concentrations, most of the MPS molecules are adsorbed close to CNF micropores, while those of VTS molecules are on defect free graphene sheets. For high silane adsorbed concentrations, MPS molecules are covering micropores as well as defect free graphene sheets, while VTS molecules are only adsorbed on these graphene sheets. These results are in line with the above discussed FTIR-ATR results where it was shown that the vinyl group of the VTS silane interacted mainly with the $\Pi$ electron rich graphene sheets and thus the $1370 \mathrm{~cm}^{-1}$ band assigned to the deformation of the $\mathrm{C}=\mathrm{CH}_{2}$ group only appeared at high silane concentrations. On the other hand, for low MPS concentrations, although such molecules are adsorbed by silanols, $\mathrm{C}=\mathrm{O}$ and $\mathrm{C}=\mathrm{C}$ groups, the $\mathrm{C}=\mathrm{O}$ groups gave a band at $1665 \mathrm{~cm}^{-1}$ assigned to $\mathrm{C}=\mathrm{O}$ hydrogen bonded interactions. This interaction must be associated with hydroxyl groups on the miropores of the CNF surface and, as a result such pores are covered with MPS molecules, confirming the low $\mathrm{S}_{\mathrm{BET}}-\mathrm{MS}_{\mathrm{BJH}}$ values. These later results are also in accordance with $\mathrm{d}_{\mathrm{BJH}}$ values of Table 2, showing that VTS molecules do not modify the average pore size of the CNF, while MPS molecules cover the small size pores and then the average pore size increases.

\subsection{FE-SEM analysis}

In Figure 8 FE-SEM micrographs of pristine $\mathrm{CNF}$ and 5\% silane coated $\mathrm{CNF}$ are shown. Pristine CNFs are long and straight, with the typical tubular microstructure which corresponds with a stacked-cup CNF structure, as it has been described by Martín-Gullón et al. [24]. As expected, this tubular microstructure is maintained after silane treatment. Due to the low interaction of the VTS silane with the CNF, the microstructure does not show any change (Figure 8-c) being possible to observe an open-ended tube. On the other hand, the 
high interaction of MPS with the CNF results evident from these micrographs (Figure 8-b). Here, the MPS coated CNF show a smooth surface which is due to the silane coating on the whole CNF surface. This coating may joins adjacent nanofibers. In both cases the silane coating seems to be uniform and no silane agglomerates are observed.
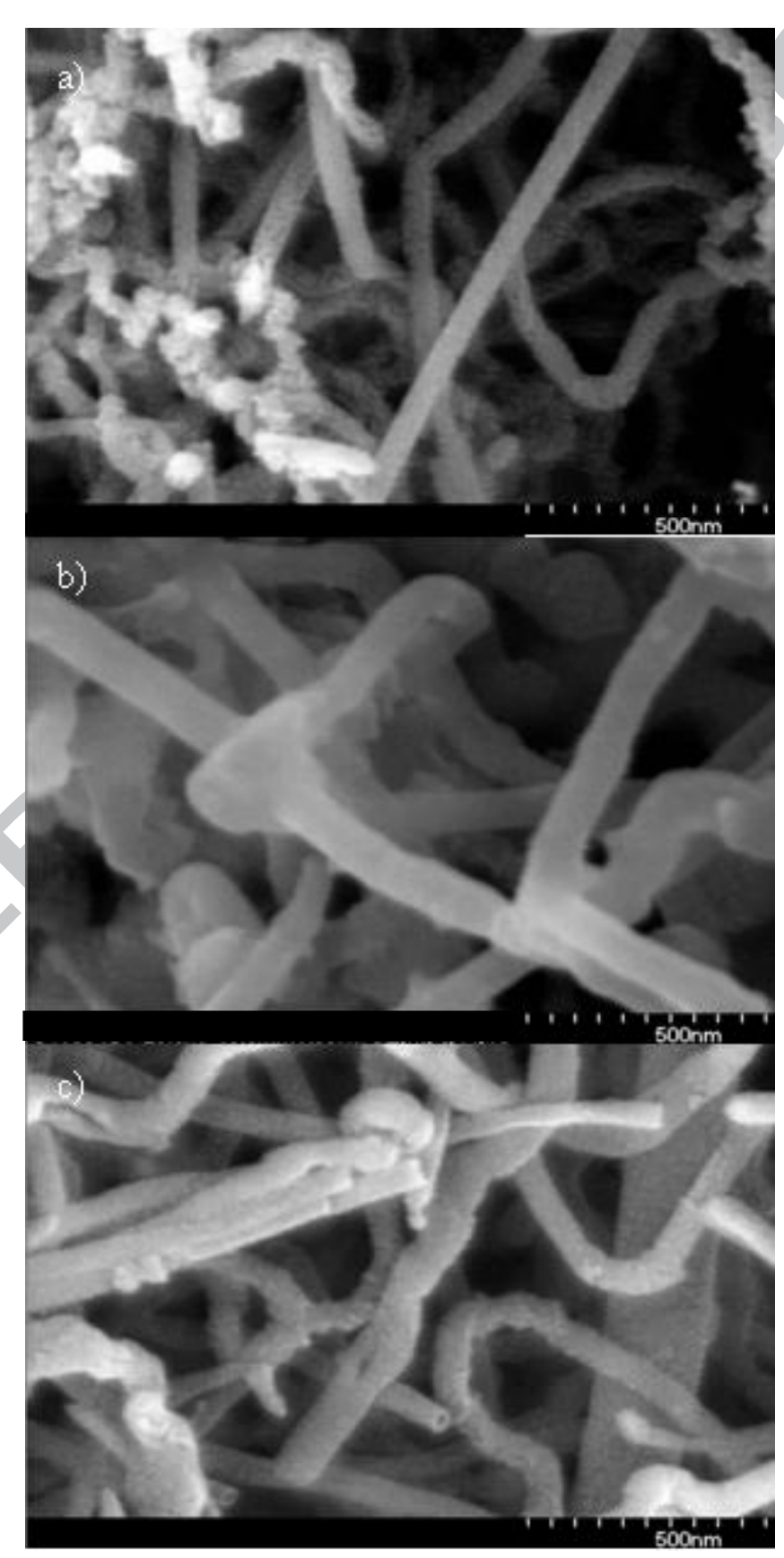
Figure 8. FE-SEM images of pristine CNF (a), 5-MPS coated CNF (b) and 5-VTS coated CNF (c).

\subsection{TEM analysis}

Conventional TEM micrographs of pristine $\mathrm{CNF}$ and 5\% (w/w) silane coated CNF are shown in Figure 9. The inner core of the stacked cup CNF can be distinguished from the graphene layers of the outer side. As it can be seen, the surface of the pristine CNF is smooth and there is no coverage on the graphene layers. On the other hand, the silane coating appears clearly for the silane coated CNF (Figure 9-b 9-c and 9-d). The coating seems homogeneous for both silanes, being more noticeable for the 5-VTS coated CNF, due to the small amount of VTS incorporated. The MPS coating seems less homogeneous, with localized increased thickness that can even stick adjacent nanofibers (Figure 9-c), as also was observed by FE-SEM microscopy (Figure 8-b). The MPS coating is thicker than the VTS one, as expected by means of ELS results obtained from TG analysis and also the blueshifts observed for the LO phonon mode for both silanes. 


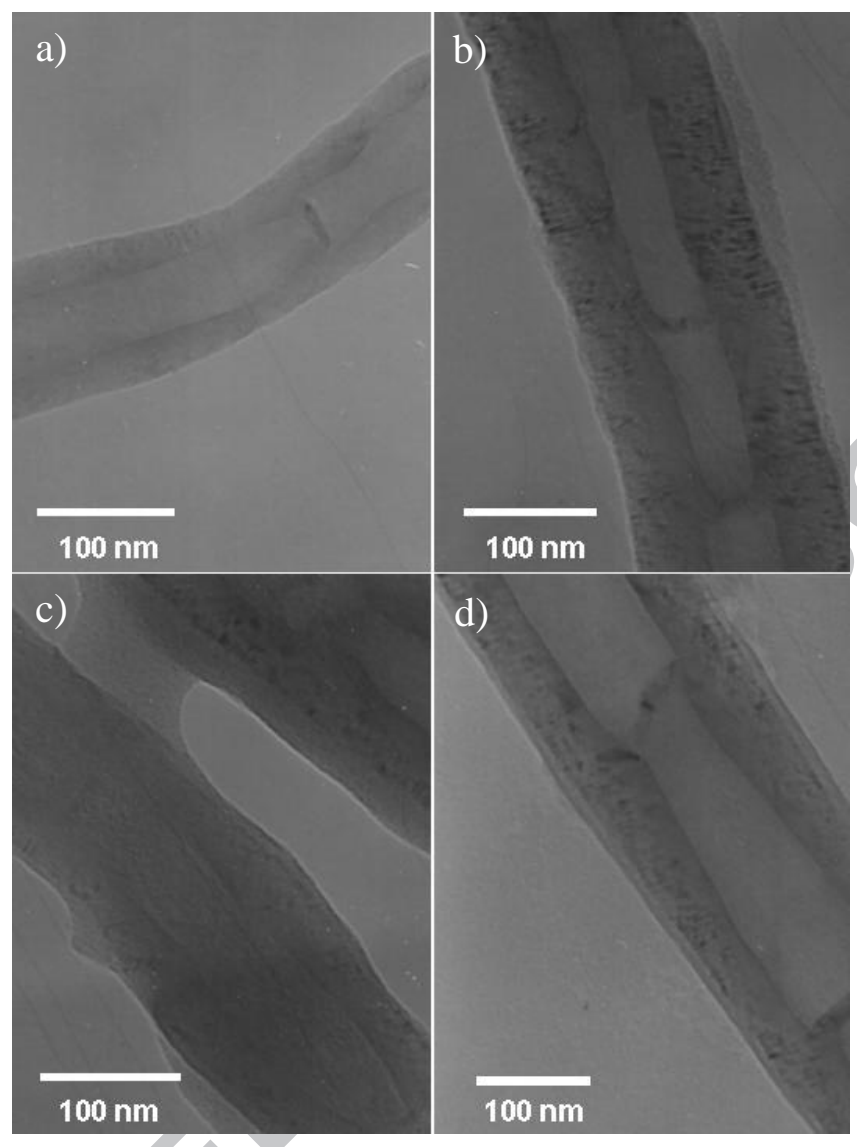

Figure 9. Conventional TEM images of pristine CNFs (a), 5-MPS coated CNFs (b and c) and 5-VTS coated CNFs (d).

HRTEM images of pristine and silane coated CNFs are shown in Figure 10. It is clear that the pristine CNF surface is smooth and, at higher magnification clearly shows the graphene planes oblique to the fiber axis [48]. On the other hand, silane coated CNFs show thicker surfaces with low inner channels, specially for the 5-MPS coated CNFs (Figure 10b). In these cases the graphene layers are not observed at higher magnifications, showing that the silanes are coating the CNF surface. 

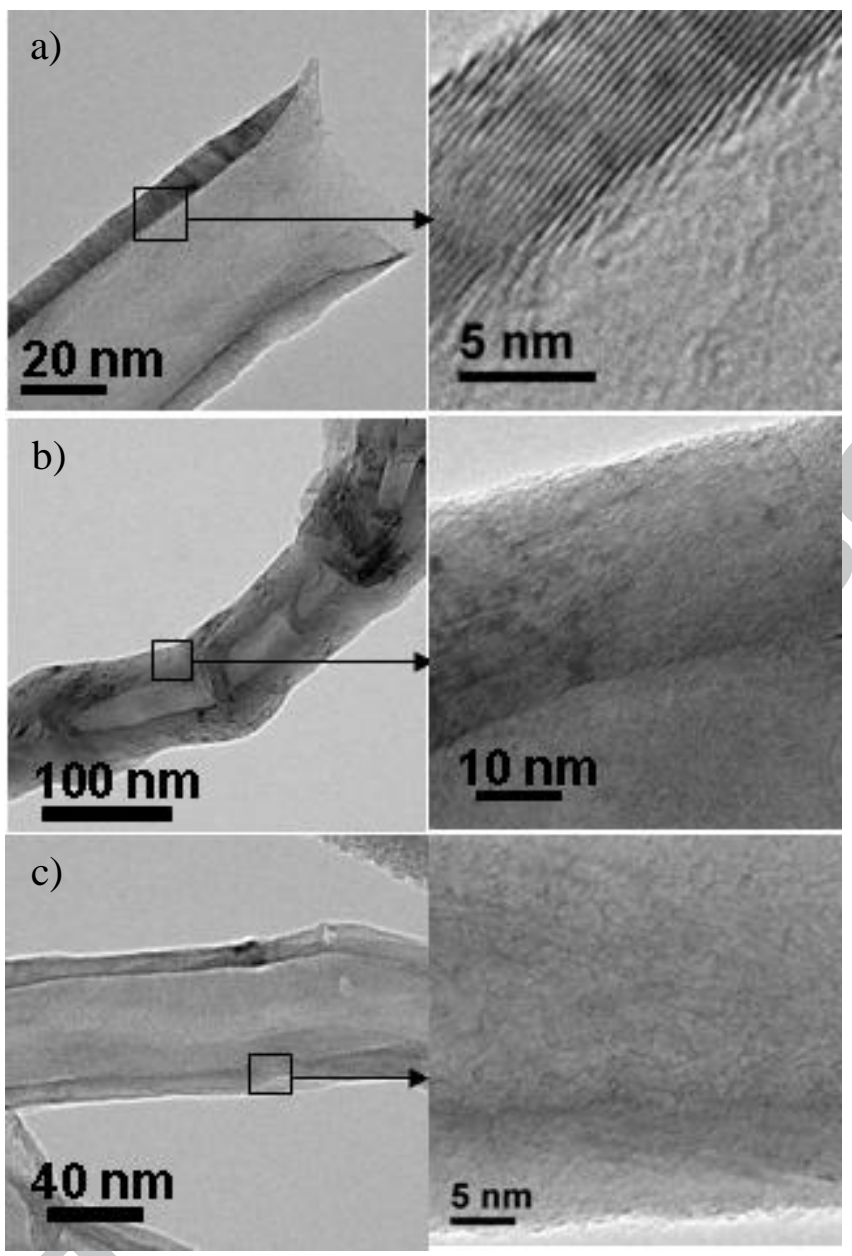

Figure 10. HRTEM images of pristine CNF (a), 5-MPS coated CNF (b) and 5-VTS coated CNF (c).

\subsection{Dispersion measurements}

Figure 11 shows the settling experiments of pristine CNF and silane coated CNF in water and styrene. From Figure 11-a it is clear that all studied dispersions are not stable in water and after approximately $0.5 \mathrm{~h}$ all CNF had settled down from the solution. A higher settle down rate appears for the 5-MPS coated CNF, a result that must be attributed to the formation of aggregates because MPS can stick single CNF as it has been observed by FESEM and TEM analysis (Figures 8-b and 9-c). 5-VTS coated CNF shows a similar behavior 
to pristine CNF, since VTS molecules are weakly bonded to the CNF surface and during the settling experiments such molecules could be desorbed to form aqueous stable micellar structures.

On the other hand, the styrene solutions seem to be more stable with time. In this case, it is surprisingly observed that VTS coated CNF is less stable in time than pristine CNF. This result might be due to the orientation of the VTS molecules adsorbed on the CNF surface. As it has been mentioned, the interaction of the VTS vinyl group on the CNF surface is favored and then there remain silanol groups outermost the CNF surface. These polar silanol groups in the presence of a non-polar solvent such as styrene give a tendency to form aggregates that sediment more quickly in such solution. On the other hand, MPS coated CNF are very stable in styrene, up to $24 \mathrm{~h}$. As it has also been discussed by FT-IR results, MPS coated $\mathrm{CNF}$ present $\mathrm{C}=\mathrm{O}$ and $\mathrm{C}=\mathrm{C}$ free bonds showing that the methacryloxypropyl chain is now located outermost the CNF surface. This organic chain is less polar than the silanol one of the VTS silane and, therefore the stability of the CNF coated with MPS is higher. The presence of free $\mathrm{C}=\mathrm{O}$ groups that give some polar character may be the result of the observed settle down in Figure 10-b corresponding to 5-MPS. Non hydrolysable group of the MPS is mostly oriented outermost the CNF surface and, the interaction with styrene is quite stable, so no CNF agglomerates are formed and as a result it sediments very little compared to pristine CNF or VTS coated CNF.

In accordance with the results of Figure 11, most VTS or MPS molecules are coated physically on the surface of CNF. Therefore, in order to bind them chemically onto CNF surface there must be analyze new ways as for example using catalysts or changing the treatment conditions such as reaction temperature and time and, finally washing off the unbound products with a proper solvent to obtain covalent-functionalized products. 

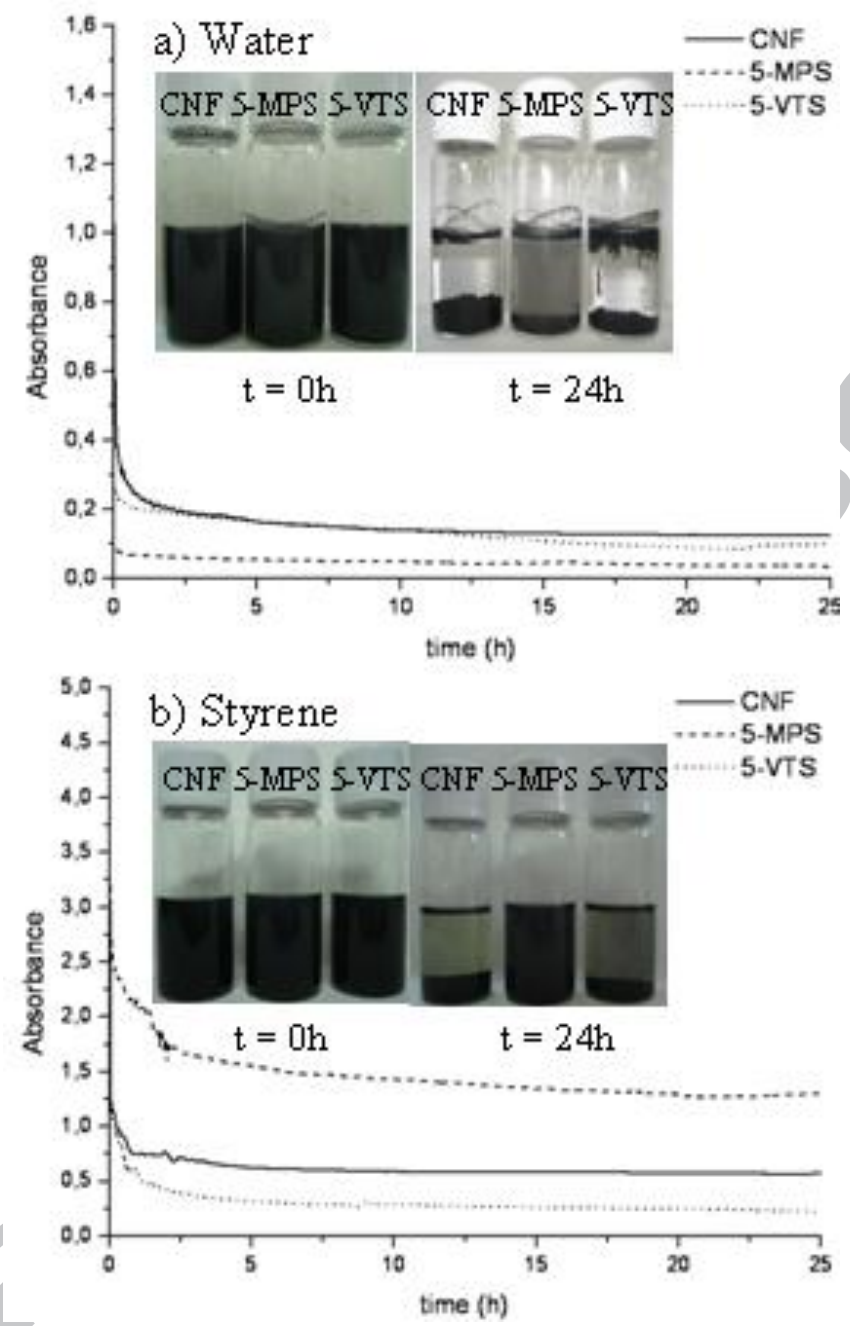

Figure 11. Absorbance at $667 \mathrm{~nm}$ of the pristine and silane coated CNF predispersed suspensions in water (a) and styrene (b).

\section{Conclusions}

CNFs are modified by vinyl and carbonyl silanes in aqueous solutions. It is observed that for a given silane concentration solution, MPS adsorbs three times than VTS silane. For these silane coatings, most accessible silane molecules are thermally degraded between 250 $280{ }^{\circ} \mathrm{C}$ however, the inner ones are degraded between $310-330{ }^{\circ} \mathrm{C}$. The presence of silane molecules coating other silane molecules do not necessary lead to the formation of a silica 
layer on the CNF surface. The silica layer formation is only observed by the blue-shift of the LO phonon mode of the Si-O-Si FTIR-ATR band which appears at $1250 \mathrm{~cm}^{-1}$. VTS silane adsorbs on the CNF surface mainly by its vinyl group, while MPS silane adsorbs also by the carbonyl one. However, as the silane adsorbed concentration increases, more vinyl and carbonyl groups are observed as free groups, showing that silane interactions take place through silanol groups. These interactions are responsible for the silica layer formation. The adsorption of both silanes on the CNF surface results in a decrease of the CNF surface area however, MPS silane is more adsorbed close to or in the micropores. Thus, while VTS is adsorbed on the defect free graphene surface and then the micropores are not coated, however MPS is adsorbed mainly on or close to the micropores. It is then assumed that the vinyl group of VTS is adsorbed on the CNF surface through П-П interactions, while MPS adsorbs on hydroxyl groups through silanol-hydroxyl and carbonyl-hydroxyl interactions. These different silane adsorptions are in line with silane modified CNF dispersions on water and styrene solvents.

\section{$\underline{\text { Acknowledgements }}$}

The authors thank C. Merino from Grupo Antolín Ingeniería S.A. for supplying GANF CNFs and I. Martín-Gullón from the University of Alicante for the HRTEM micrographs and discussion. The authors also thank the Ministerio de Ciencia e Innovación and Centro para el Desarrollo Tecnológico Industrial (CDTI) for financially supporting this research under Project CENIT DOMINO No. CEN-2007-1001. 


\section{$\underline{\text { References }}$}

[1] Iijima S. Helical microtubules of graphitic carbon. Nature 1991; 354 (6348): 56-8.

[2] Wong EW, Sheehan, PE, Lieber CM. Nanobeam mechanics: elasticity, strength, and toughness of nanorods and nanotubes. Science 1997; 277(5334): 1971-5.

[3] Thostenson ET, Ren Z, Chou TW. Advances in the science and technology of carbon nanotubes and their composites: a review. Compos. Sci. Technol. 2001; 61(13): 1899-912. [4] Al-Saleh MH, Sundararaj U. A review of vapour grown carbon nanofiber/polymer conductive composites. Carbon 2009; 47(1): 2-22.

[5] Xie XL, Mai YW, Zhou XP. Dispersion and alignment of carbon nanotubes in polymer matrix: a review. Mater. Sci. Eng. R 2005; 49(4): 89-112.

[6] Hirsch A. Functionalization of single-walled carbon nanotubes. Angew. Chem. Int. Ed. 2002; 41(11): 1853-9.

[7] Li J, Vergne MJ, Mowles ED, Zhong WH, Hercules DM, Lukehart CM. Surface functionalization and characterization of graphitic carbon nanofibers (GCNFs). Carbon 2005; 43(14): 2883-93.

[8] Vaisman L, Wagner HD, Marom G. The role of surfactants in dispersion of carbon nanotubes. Adv. Colloid Interface Sci. 2006; 128-130: 37-46.

[9] O’Connell MJ, Boul P, Ericson LM, Huffman C, Wang Y, Haroz E, et al. Reversible water-solubilization of single-walled carbon nanotubes by polymer wrapping. Chem. Phys. Lett. 2001; 342(3-4): 265-71.

[10] Niyogi S, Hamon MA, Hu H, Zhao B, Bhowmic P, Sen R, et al. Chemistry of singlewalled carbon nanotubes. Acc. Chem. Res. 2002; 35(12): 1105-13.

[11] Sham ML, Kim JK. Surface functionalities of multi-wall carbon nanotubes after UV/Ozone and TETA treatments. Carbon 2006; 44(4): 768-77. 
[12] Valentini L, Macan J, Armentano I, Mengoni F, Kenny JM. Modification of fluorinated single-walled carbon nanotubes with aminosilane molecules. Carbon 2006; 44(11): 2196-201. [13] Ishida H, Koenig JL. Fourier transform infrared spectroscopic study of the structure of silane coupling agent on E-glass fiber. J. Colloid Interface Sci. 1978; 64(3): 565-76.

[14] Ishida H, Koenig JL. An investigation of the coupling agent/matrix interface of fiberglass reinforced plastics by Furier transform infrared spectroscopy. J. Polym. Sci. Polym. Phys. Ed. 1979; 17(4): 615-26.

[15] Ishida H, Koenig JL. A Fourier-transform infrared spectroscopic study of the hydrolytic stability of silane coupling agents on E-glass fibers. J. Polym. Sci. Polym. Phys. Ed. 1980; 18(9): 1931-43.

[16] Ishida H, Koenig JL. Effect of hydrolysis ad drying in the siloxane bonds of a silane coupling agent deposited on E-glass fiber. J. Polym. Sci. Polym. Phys. Ed. 1980; 18(2): 2337.

[17] Graf RT, Koenig JL, Ishida H. Characterization of silane-treated glass fibers by diffuse reflectance Fourier transform spectrometry. Anal. Chem. 1984; 56(4): 773-8.

[18] Velasco-Santos C, Martínez-Hernández AL, Lozada-Cassou M, Alvarez-Castillo A, Castaño VM. Chemical functionalization of carbon nanotubes through an organosilane. Nanotechnology 2002; 13(4): 495-8.

[19] Ma PC, Kim JK, Tang BZ. Functionalization of carbon nanotubes using a silane cupling agent. Carbon 2006, 44(15), 3232-8.

[20] Bag DS, Dubey R, Zhang N, Xie J, Varadan VK, Lal D, et al. Chemical functionalization of carbon nanotubes with 3-methacryloxypropyltrimethoxysilane (3-MPTS). Smart. Mater. Struct. 2004; 13(5):1263-7. 
[21] Ma PC, Kim JK, Tang BZ. Effects of silane functionalization on the properties of carbon nanotube/epoxy composites. Compos. Sci. Technol. 2007; 67(14): 2965-72.

[22] Zhou Z, Wang S, Lu L, Zhang Y, Zhang Y. Functionalization of multi-wall carbon nanotubes with silane and its reinforcement polypropylene composites. Compos. Sci. Technol. 2008; 68(7-8): 1727-33.

[23] Palencia C, Rubio F, Merino C, Rubio J, Oteo JL. Study of the silanization process in CNFs: time, temperature, silane type and concentration influence. J. Nano Res. 2008; 4: 3343.

[24] Martín-Gullón I, Vera J, Conesa JA, González JL, Merino C. Differences between carbon nanofibers produced using $\mathrm{Fe}$ and $\mathrm{Ni}$ catalysts in a floating catalyst reactor. Carbon 2006; 44(8): 1572-80.

[25] Shih PTK, Koenig JL. Raman studies of the hydrolysis of silane coupling agents. Mater. Sci. Eng. 1975; 20(2): 137-43.

[26] Gregg SJ, Sing KSW. Adsorption, Surface area and Porosity. Academic Press. London. 1982.

[27] Sellitti C, Koenig JL, Ishida H. Surface characterization of carbon fibers by attenuated total reflection Fourier transform infrared spectroscopy. Carbon 1990; 21 (1): 221-8. [28] Scheibe B, Borowiak-Palen E, Kalenczuk RJ. Oxidation and reduction of multiwalled carbon nanotubes-preparation and characterization. Mater. Charact. 2010; 61(2): 185-91. [29] Naviroj S, Culler SR, Koenig JL, Ishida H. Structure and adsorption characteristics of silane coupling agents on silica and E-glass fiber; dependence on $\mathrm{pH}$. J. Colloid Interface Sci. 1984; 97(2): 308-17.

[30] Miller JD, Ishida H. Quantitative monomolecular coverage of inorganic particulates by methacryl-functional silanes. Surface Science 1984; 148(2-3): 601-62. 
[31] Yoon CM, Long D, Jang SM, Qiao W, Ling L, Miyawaki J, et al. Electrochemical surface oxidation of carbon nanofibers. Carbon 2011; 49(1): 96-105.

[32] Rodríguez MA, Liso JM, Rubio F, Rubio J, Oteo JL. Study of the reaction of $\gamma$ methacryloxypropyltrimethoxysilane ( $\gamma$-MPS) with slate surfaces. J. Mater. Sci. 1999; 34(16): $3867-73$

[33] Pantoja M, Díaz-Benito B, Velasco F, Abenojar J, del Real JC. Analysis of hydrolysis process of $\gamma$-methacryloxypropyltrimethoxysilane and its influence on the formation of silane coatings on 6063 aluminum alloy. Appl. Surf. Sci. 2009; 255(12): 6386-90.

[34] Bourgeat-Lami E, Lang J. Encapsulation of inorganic particles by dispersion polymerization in polar media. J. Colloid Interface Sci. 1998; 197(2): 293-380. [35] Sondi I, Fedynyshyn TH, Sinta R, Matijevic E. Encapsulation of nanosized silica by in situ polymerization of tert-butyl acrylate monomer. Langmuir 2000; 16(23): 9031-4. [36] Ishida H, Koenig JL. Fourier Transform infrared spectroscopic study of the silane coupling agent/porous silica interface. J. Colloid Interface Sci. 1978; 64(3): 555-64. [37] Tian R, Seitz O, Li M, Hu W, Chabal YJ, Gao J. Infrared characterization of interfacial Si-O bond formation on silanized flat $\mathrm{SiO} 2 / \mathrm{Si}$ surfaces. Langmuir 2010; 26(7): 4563-6. [38] Lange P, Schnakenberg U, Ullerich S, Schliwinski HJ. Disorder in vitreous SiO2: the effect of thermal annealing on structural properties. J. Appl. Phys. 1990; 68(7): 3532-7. [39] Lange P. Evidence for disorder-induced vibrational mode coupling in thin amorphous SiO2 films. J. Appl. Phys. 1989; 66(1): 201-4.

[40] Berreman DW. Infrared absorption at longitudinal optic frequency in cubic crystal fimls. Phys. Rev. 1963; 130(6): 2193-8. 
[41] Pasternack RM, Amy SR, Chabal YJ. Attachment of 3-(aminopropyl)triethoxysilane on silicon oxide surfaces: dependence on solution temperature. Langmuir 2008; 24(22): 1296371.

[42] Maciel GE, Sindorf DW. Silicon-29 nuclear magnetic resonance study of the surface of silica gel by cross polarization and magic-angle spinning. J. Am. Chem. Soc. 1980; 102(25): $7606-7$

[43] Morrow BA, Gay ID. Silicon-29 cross-polarization/magic angle spinning NMR evidence for geminal silanols on vacuum-activated aerosil silica. J. Phys. Chem. 1988; 92(20): 556971.

[44] Tripp CP, Hair ML. Reaction of chloromethylsilanes with Silica: a low-frequency infrared study. Langmuir 1991; 7(5): 923-7.

[45] Ishida H, Miller JD. Substrate effects on the chemisorbed and physisorbed layers of methacryl silane modified particulate minerals. Macromolecules 1984; 17(9): 1659-66. [46] Endo M, Kim YA, Takeda T, Hong SH, Matusita T, Hayashi T, et al. Structural characterization of carbon nanofibers obtained by hydrocarbon pyrolysis. Carbon 2001; 39(13): 2003-10.

[47] Ligner D, Sidqi M, Jagiello J, Balard H, Papirer E. Characterization of specific interactions capacity of solid surfaces by adsorption of alkanes and alkenes. II: adsorption on crystalline silica layer surfaces. Chromatographia 1990; 29(1, 2): 35-38.

[48] Vera-Agulló J, Varela-Rizo H, Conesa JA, Almansa C, Merino C, Martín-Gullón I. Evidence for growth mechanism and helix-spiral cone structure of stacked-cup carbon nanofibers. Carbon 2007; 45(14): 2751-8. 


\section{List of Captions for Figures and Tables}

Figure 1: TGA of CNF coated with MPS and VTS.

Figure 2: First derivative plots of TGA of CNF coated with MPS and VTS.

Figure 3: FTIR-ATR spectrum of pristine CNFs and difference spectra of MPS coated CNFs.

Figure 4: Relation in intensity of the bands associated to $\mathrm{C}=\mathrm{C}$ and $\mathrm{C}=\mathrm{O}$ groups is plotted against the equivalent layers of MPS on the silanized CNF (line is only for guiding the eye). Figure 5: FTIR-ATR spectrum of pristine CNFs and difference spectra of VTS coated CNFs.

Figure 6: Schematic approach to the orientation of the silanes on the CNF surface, for low concentration of MPS (a), high concentration of MPS (b), low concentration of VTS (c) and high concentration of VTS $(d)$

Figure 7: $\mathrm{N}_{2}$ adsorption-desorption isotherms of CNF coated with MPS (a) and VTS (b) coupling agents.

Figure 8: FE-SEM images of pristine CNF (a), 5-MPS coated CNF (b) and 5-VTS coated CNF (c).

Figure 9: Conventional TEM images of pristine CNF (a), 5-MPS coated CNF (b and c) and 5-VTS coated CNF (d).

Figure 10. HRTEM images of pristine CNF (a), 5-MPS coated CNF (b) and 5-VTS coated CNF (c).

Figure 11: Absorbance at $667 \mathrm{~nm}$ of the pristine and silane coated CNF predispersed suspensions in water (a) and styrene (b).

Table 1: TG results for the incorporation of SCA on CNF. (IDT: Initial decomposition temperature. EDT: Ending decomposition temperature). 
Table 2: $\mathrm{S}_{\mathrm{BET}}$ area, mesopore surface area $\left(\mathrm{MS}_{\mathrm{BJH}}\right)$ and average pore diameter $\left(\mathrm{d}_{\mathrm{BJH}}\right)$ for the pristine and silane coated $\mathrm{CNF}$. 
- Carbon nanofiber (CNF) surface and silane coupling agent (SCA) interacts

- These interactions are determined by SCA structure and concentration

- CNF-SCA interactions determine the orientation of SCA with respect to CNF surface

- The orientation of SCA with respect to CNF modifies CNF surface properties

- Stable SCA coated CNF suspension is achieved 